\title{
ANATOMIA DA MADEIRA DO GUAMIRIM-FACHO, Calyptranthes concinna DC.
}

\section{WOOD ANATOMY OF Calyptranthes concinna DC. (Myrtaceae).}

\author{
José Newton Cardoso Marchiori ${ }^{1}$ Eliége Terezinha Brum ${ }^{2}$
}

RESUMO

O objetivo do presente trabalho é a descrição anatômica da madeira de Calyptranthes concinna DC. São também fornecidas fotomicrografias e dados quantitativos de detalhes anatômicos. As principais características observadas na madeira são citadas pela literatura como típicas para a família Myrtaceae. Destacam-se a presença de placas de perfuração simples, de pontuações areoladas pequenas e ornamentadas e a ausência de cristais no parênquima lenhoso.

Palavras-chave: anatomia da madeira, Myrtaceae, Calyptranthes concinna, guamirim-facho.

\section{SUMMARY}

The wood anatomy of Calyptranthes concinna DC. is described in this paper. Photomicrographs and quantitative date of the anatomical structure are presented. The most important anatomical features observed in the wood are common for the Myrtaceae family. Among these features are included the presence of simple perforation plates in vessel members, small and vestured vessel-pits and the absence of crystals in the wood parenchyma.

Key words: wood anatomy, Myrtaceae, Calyptranthes concinna.

\section{INTRODUÇÃO}

O Gênero Calyptranthes Sw. compreende cerca de 100 espécies, que se distribuem pela América tropical, desde o sul da Flórida até o Uruguai. O nome vem do grego calyptra (tampa) e anthum (flor), referindo-se à ruptura circular do cálice na ântese, que produz uma estrutura posteriormente caduca, à semelhança de uma tampa. No Estado de Santa Catarina são registradas 14 espécies nativas (LEGRAND \& KLEIN, 1971) e destas, apenas sete alcançam o Rio Grande do Sul (MATTOS, 1983).

A espécie em estudo é um arbusto ou árvore de até $5,0 \mathrm{~m}$, com tronco geralmente tortuoso e casca acinzentada. É conhecida popularmente pelos nomes de guamirim-facho, guamirim ou camboim-ferro. Sua distribuição geográfica abrange o Planalto Sulbrasileiro e o Uruguai (LOMBARDO, 1964), crescendo principalmente em matas ciliares e capões. Prefere solos aluviais, úmidos e compactados, sendo uma heliófita e seletiva higrófita (LEGRAND \& KLEIN, 1971).

A literatura anatômica sobre as mirtáceas brasileiras é fragmentária, inexistindo um estudo abrangente das mesmas. Para poucas espécies existem descrições microscópicas da madeira, destacando-se neste particular os trabalhos sobre Feijoa sellowiana Berg (MARCHIORI, 1984a), Eugenia involucrata DC. (MARCHIORI, 1984b), Myrrhinium loranthoides (Hook. et Arn.) Burr. (MARCHIORI, 1984c), Myrciaria tenella (DC.) Berg (MARCHIORI \& MUÑIZ, 1987), Myrceugenia myrtoides Berg (MARCHIORI, 1987) e Myrceugenia glaucescens (Camb.) Legr. et Kaus. (MARCHIORI \& MUÑIZ, 1988).

\footnotetext{
${ }^{1}$ Engenheiro Florestal, Professor Titular, Dr., Departamento de Ciências Florestais, Centro de Ciências Rurais (CCR), Universidade Federal de Santa Maria (UFSM), 97119-900 - Santa Maria, RS. Autor para correspondência.
}

${ }^{2}$ Engenheiro Florestal, Professor Adjunto, MsC., Departamento de Ciências Florestais, CCR, UFSM. 
Com relação ao gênero Calyptranthes são muito escassas as referências anatômicas, inexistindo descrições sobre espécies brasileiras. METCALFE \& CHALK (1972) citam, para o gênero, a ocorrência de vasos tipicamente solitários, de ocasionais múltiplos com duas ou três células e freqüência de 40 a 100 poros por $\mathrm{mm}^{2}$. São ainda referidos raios de quatro a seis células de largura e uma a três fileiras marginais de células eretas, bem como uma frequiência inferior a 13 raios por $\mathrm{mm}$, em algumas espécies.

Para a família Myrtaceae como um todo, RECORD \& HESS (1949) destacam placas de perfuração simples, pontuações ornamentadas, traqueóides vasicêntricos e raios nitidamente heterogêneos. Os autores também relacionam a ausência de espessamentos espiralados em vasos, citando como exceção duas espécies de Myrceugenia.

A madeira de Calyptranthes concinna DC. é moderadamente pesada, dura e de fibras entrecruzadas. Devido ao reduzido diâmetro, os troncos são utilizados apenas como lenha ou para a confecção de pequenas peças. Sua estrutura anatômica é desconhecida, sendo o presente trabalho provavelmente o primeiro estudo sobre o tema.

\section{MATERIAIS E MÉTODOS}

O material analisado é procedente do Rio Grande do Sul e consiste de duas amostras de madeira, conservadas no Herbário do Departamento de Ciências Florestais (HDCF) com os seguintes registros:

HDCF 2.254, fazenda Vista Alegre, São Sepé, RS (Marchiori, J.N.C. n? 302, 15/01/86); e HDCF 3.008, Parque Estadual do Turvo, Tenente Portela, RS (Marchiori, J.N.C. n? 628, 12/11/86).

Do material lenhoso de cada uma das amostras, foram preparados três corpos de prova, orientados para a obtenção de cortes anatômicos nos planos transversal, longitudinal radial e longitudinal tangencial. $\mathrm{O}$ amolecimento dos mesmos foi realizado por fervura em água e a obtenção de cortes em micrótomo de deslizamento, adotando-se a espessura nominal de $18 \mu \mathrm{m}$. Usou-se tripla coloração, com acridina-vermelha, crisoidina e azul de astra (DUJARDIN, 1964) e montagem de lâminas permanentes, com Entellan. Para o preparo de lâminas de macerado procedeu-se a dissociação do tecido lenhoso pelo método de Jeffrey (FREUND, 1970). Usou-se coloração com safranina e o mesmo meio de montagem anteriormente citado.

A terminologia adotada, as medições e descrição da estrutura anatômica, seguiram as recomendações da COPANT (1973). Para a determinação da percentagem dos diferentes tipos celulares, usou-se a metodologia recomendada por MARCHIORI (1980). Os dados quantitativos e determinações estereológicas são apresentadas na Tabela 1. As fotomicrografias foram tomadas em aparelho Carl Zeiss, no Laboratório de Anatomia da Madeira, da Universidade Federal do Paraná.

\section{DESCRIÇÃO MICROSCÓPICA}

Vasos: Numerosos (9 - 11- 16 poros $/ \mathrm{mm}^{2}$ ), em distribuição difusa-uniforme (Figura 1.a), e ocupando 3,7\% da secção transversal da madeira. Poros muito pequenos até pequenos $(35-58-79 \mu \mathrm{m})$, solitários, de secção circular ou oval (Figura 1.b-d) e com paredes de 2,5 - 2,7 - 3,8 $\mu$ m de espessura. Elementos vasculares curtos até longos (300 - 510 $680 \mu \mathrm{m})$ e providos de apêndices curtos (7,5 - 65 $190 \mu \mathrm{m})$, em uma ou em ambas extremidades. Placas de perfuração simples, geralmente oblíquas aos vasos. Pontoações intervasculares ausentes. Pontoações raiovasculares em arranjo alterno, muito pequenas (2,5 $3,4-4 \mu \mathrm{m})$, arredondadas, ornamentadas e com abertura exclusa. Pontoações parênquimo-vasculares de muito pequenas até pequenas $(3-3,6-4,5 \mu \mathrm{m})$, semelhantes às raio-vasculares. Gomas, resina, tilos e outros conteúdos, ausentes nos poros (Figura 1.c-d) e vasos.

Parênquima axial : Abundante, ocupando $25,4 \%$ da secção transversal da madeira. Células parenquimáticas em distribuição apotraqueal subagregada e zonada (Figura 1.c-d), formando linhas tangenciais com uma célula de espessura. Células parenquimáticas retangulares de 67 - 103 - 148 $\mu \mathrm{m}$ de altura por 12,5 - 15,7 - 18,8 $\mu$ m de largura, dispostas em séries verticais não estratificadas de quatro - cinco oito células e 420 - 526 - $613 \mu \mathrm{m}$ de altura (Figura 2.d).

Raios: Muito numerosos $(24,2 / \mathrm{mm})$ e ocupando $23,4 \%$ do volume da madeira. Tecido radial heterogêneo, composto por raios unisseriados e multisseriados. Os raios unisseriados são predominantes na madeira $(64 \%)$, extremamente finos $(8,7-12,7-24 \mu \mathrm{m})$, baixos (107 - 241 $413 \mu \mathrm{m})$ e com 1 - 5 - 10 células de altura. Os multisseriados são muito finos (12,5 - 19 - 26 $\mu \mathrm{m})$, geralmente bisseriados $(34,7 \%)$ e raramente trisseriados (1,3\%). Apresentam de 7 - 12 - 22 células de altura, uma curta parte multisseriada

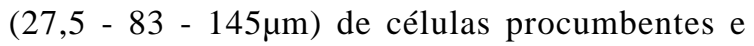
margens unisseriadas relativamente longas, compostas de células quadradas e principalmente eretas (Figura 2.c,d). Células cristalíferas, envolventes e esclerosadas, ausentes no tecido radial (Figura 2. a,b). Presença abundante de gomo-resina nas células dos raios (Figura 1.b; 2.a). 


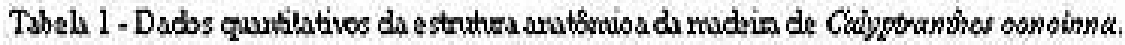

\begin{tabular}{|c|c|c|c|c|}
\hline CARACTERIST CA ANATOMLA. & VALORMAMMMO & MíDIA. & VALOR MAXIMO & $\begin{array}{l}\text { DESVIO } \\
\text { PADRE }\end{array}$ \\
\hline 1. Freqitrroiad ponse (porotirann') & 90 & 11 & $\frac{16}{60}$ & $\begin{array}{l}306 \\
200\end{array}$ \\
\hline 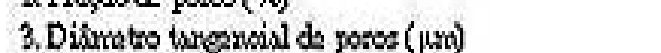 & 35,0 & 580 & 20 & 11,11 \\
\hline 4. Espessua parede de poms (um) & 25 & 27 & 3,8 & 0,36 \\
\hline 5. Compaimento alementos vasulares (Jum) & 3000 & $\$ 100$ & 680,0 & 94,64 \\
\hline 6. Corrpimento de apéntices ( $\mu \mathrm{m})$ & 7,5 & 65,0 & 190,0 & 39,96 \\
\hline 7. Diarmeto postos coces raio-vasculdares (pm) & 25 & 34 & 40 & 0,47 \\
\hline 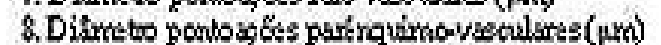 & 30 & 36 & 45 & 0,45 \\
\hline 9. Frasão parenchima axial $(\%)$ & 21,0 & 25,4 & 35,0 & 4,79 \\
\hline 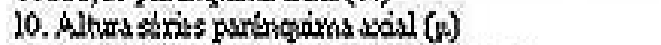 & 4200 & $\$ 260$ & 6130 & 57,3 \\
\hline 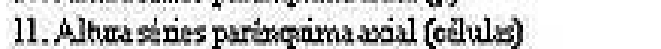 & 4 & 5 & 8 & 1,49 \\
\hline 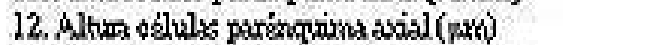 & 67,0 & 1030 & 1480 & 25,10 \\
\hline 13. Largura cadulas parercquima aval ( $\mu \mathrm{m})$ & 125 & $15 ?$ & 188 & 237 \\
\hline 14. Fng io tosido radill $(\%)$ & 180 & 234 & 23,0 & 3,20 \\
\hline 1S. Frequirncia de raios (raicosirmul) & 200 & 24,2 & 20 & 2,S1 \\
\hline 16. Frap so raios unissenados $(\%)$ & 620 & 64,0 & 66,0 & 1,82 \\
\hline 17. Altura rios nuisogiados (urn) & 1070 & 2410 & 4130 & S3 34 \\
\hline 18. Althra raioswrisseriados (célulks) & 1 & 5 & 10 & 242 \\
\hline 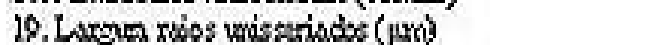 & 87 & 127 & 24,0 & 270 \\
\hline DD. Fraç ä́ aios bisseriados (\%) & 320 & 34,7 & 37,0 & 2,21 \\
\hline 11. Fraçäo ridos tiossriados (\%) & 1,0 & 1,3 & 20 & 0,50 \\
\hline 22. Al thra nios roultiospriados (pra) & 1820 & 3440 & 2080 & 119,55 \\
\hline 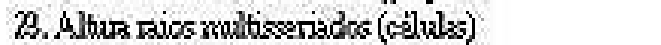 & 7 & 12 & 22 & 3,21 \\
\hline 24. Albra pante yultisseriada $(\mu x h)$ & 27,5 & 830 & 1450 & 3660 \\
\hline 2S. Alturas garte mulitessriada (cillulas) & 2 & 5 & 9 & 1,63 \\
\hline W. Largua räos roultioseriacise ( & 125 & 19,0 & 20,0 & 335 \\
\hline 27. Largura nacs roultissenabos (callias) & 20 & 2,1 & 30 & 0,35 \\
\hline 28. Frosos de sibue $(9)$ & 91,0 & 47,5 & 51,0 & 4,21 \\
\hline D. Comprimerto de fibas $(\mu x)$ & 600 & \$9\%, & $1.190,0$ & $107 \%$ \\
\hline 3. Diametro de fibras $(y x x)$ & 10,0 & 11,8 & 15,0 & 1,37 \\
\hline 31. Diâxceto do lume de fibres (uxc) & 25 & 4,6 & 88 & 1,23 \\
\hline 32. Espesoura garede de fibras ( $\mathrm{mm}$ ) & 25 & 36 & $\$, 0$ & 0,54 \\
\hline
\end{tabular}

Fibras: Tecido fibroso proeminente na madeira $(47,5 \%)$, composto por fibrotraqueídeos de pontoações areoladas muito pequenas e aberturas cruzadas em X no par. Fibrotraqueídeos muito curtos até curtos $(650$ - 999 - 1.190um), estreitos $(10-11,8-15 \mu \mathrm{m})$ e com

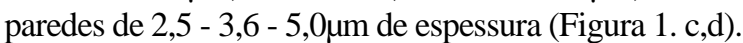

Outros caracteres Anéis de crescimento distintos, marcados por uma faixa de fibras no lenho

\section{ANÁLISE DA ESTRUTURA ANATÔMICA}

As principais características anatômicas da madeira de Calyptranthes concinna, tais como a ocorrência de poros solitários, de parênquima apotraqueal, de placas de perfuração simples, de pontoações alternas ornamentadas e de raios nitidamente heterogêneos são tidos, por METCALFE \& CHALK (1972), como bastante frequientes em Mirtáceas.

A ocorrência exclusiva de placas de perfuração simples nos vasos de Calyptranthes concinna, também é um aspecto anatômico predominante nesta família botânica e sub-família Myrtoideae, de acordo com RECORD \& HESS (1949) e METCALFE \& CHALK (1972). A literatura cita como exceção, a presença do caráter em cerca de 40 espécies, pertencentes a sete gêneros distintos (SCHMID \& BAAS, 1984). Dentre

Ciência Rural, v. 27, n. 2, 1997. 


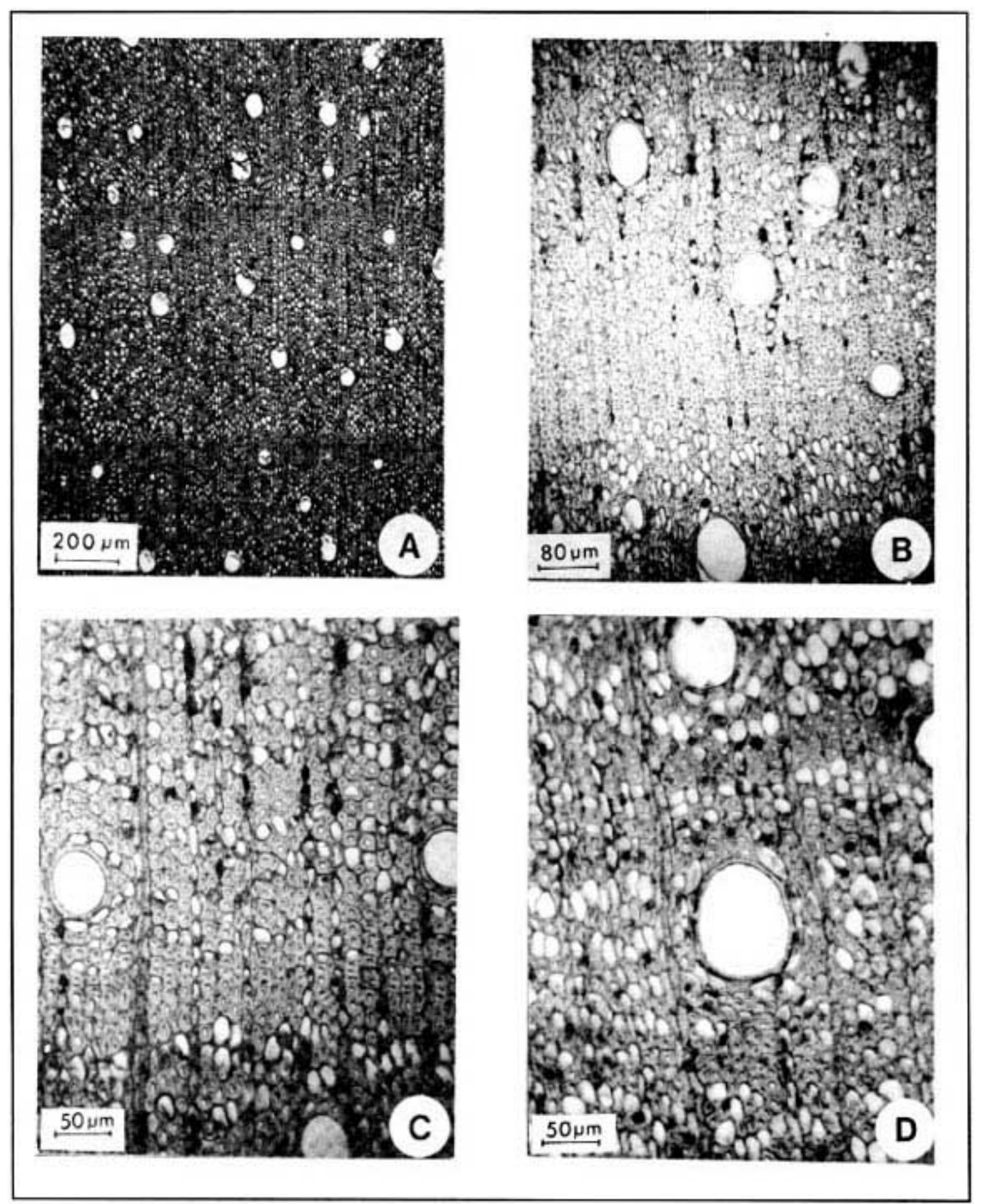

Figura I - Fotomicrografias da seç̧ao transversal da madeira de Calyptranthes concinna.

A. Limites de anel de crescimento, porosidade difusa-uniforme e parénquima apotraqueal.

B. Poros solitarios, de seç̧lo circular ou oval e prsença de gomo-resina nas celulas radiais.

C. Poros solitários, circulares ou ovais, desprovidos de conteúdos; parènquima apotraqueal sub-agregado $c$ fibras de paredes espessas

D. Outro aspecto da madeira em corte transversal, destacando poros solitários, parẻnquima apotraqueal sub-agregado e fibras de paredes espessas.

Ciência Rural, v. 27, n. 2, 1997. 


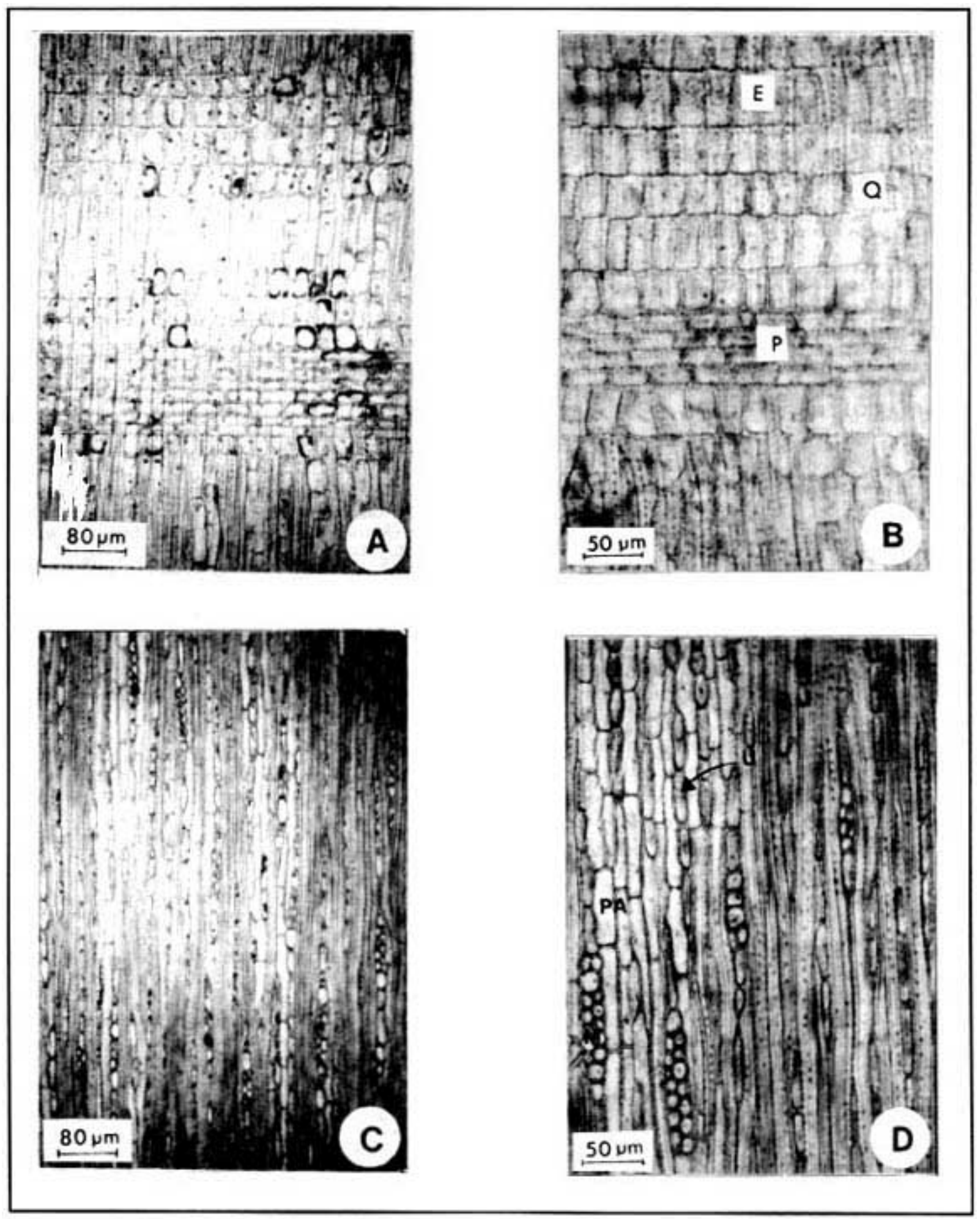

Figura 2 - Aspectos longitudinais da estrutura anatômica da madeira de Calyptranthes concinna.

A. Seçấ radial, dectacando celulas quadradas, eretas $\mathrm{e}$ procumbentes, com abundante gomo-resina

B. Distintas formas de celulas parenquimáticas radiais: Q. quadradas, E, eretas, $P$, procumbentes.

C. Seç̧o tangencial, mostrando raios multisseriados muito finos, com longas margens unisseriadas.

D. Part́nquima axiul seriado (PA), raios unisseriados (U) c multisseriados (M).

Ciência Rural, v. 27, n. 2, 1997. 
as espécies brasileiras, foram referidas placas escalariformes para as madeiras de Myrceugenia myrtoides (MARCHIORI, 1987) e Myrceugenia glaucescens (MARCHIORI \& MUÑIZ, 1988).

A presença de pontoações raio-vasculares e parênquimo-vasculares pequenas e ornamentadas, constitui igualmente um importante caráter para a identificação da espécie em estudo. Embora predominante na família, este caráter anatômico distingue-se do observado para Myrceugenia myrtoides (MARCHIORI, 1987) e Myrceugenia glaucescens (MARCHIORI \& MUÑIZ, 1988). Tratase, igualmente, de um aspecto anatômico de valor diagnóstico para a taxonomia das madeiras sulbrasileiras de mirtáceas.

São ainda valiosos para a identificação da espécie em estudo, a ausência de espessamentos espiralados nos fibrotraqueóides e de cristais no tecido lenhoso, bem como os valores quantitativos de vasos, parênquima axial, raios e fibras.

\section{CONCLUSÕES}

O estudo anatômico da madeira de Calyptranthes concinna permite extrair as seguintes conclusões:

a espécie em estudo apresenta uma grande semelhança, em seus aspectos anatômicos básicos, com o referido na literatura para a família Myrtaceae e sub-família Myrtoideae;

na espécie em estudo são observadas semelhanças e diferenças anatômicas importantes, com relação às escassas descrições anatômicas das mirtáceas sul-brasileiras;

são necessários estudos anatômicos mais aprofundados sobre o numeroso contingente de mirtáceas sul-brasileiras, com vistas ao conhecimento das possibilidades de variação anatômica das mesmas e a obtenção de inferências taxonômicas ou filogenéticas mais consistentes sobre suas madeiras.

\section{REFERÊNCIAS BIBLIOGRÁFICAS}

COPANT - COMISSÃO PANAMERICANA DE NORMAS TÉCNICAS. Descrição geral macroscópica e microscópica da madeira - esquema I de recomendação. Colômbia, 1973. 19 p. (COPANT 30)

DUJARDIN, E.P. Eine neue holz-zellulosenfaerbung. Mikrokosmos, n. 53, p. 94, 1964.

FREUND, H. Handbuch der Mikroskopie in der Technik. Frankfurt: Umsham Verlag, 1970. 379 p.

LEGRAND, D., KLEIN, R.M. Mirtáceas. 6. Calyptranthes Sw. In: REITZ, P.R. Flora Ilustrada Catarinense. Itajaí, Santa Catarina, 1971, v. 9, p. 491-552.

LOMBARDO, A. Flora arborea y arborescente del Uruguay. Montevideo: Concejo Departamental, 1964. 151 p.

MARCHIORI, J.N.C. Comprovação da viabilidade de utilização da secção longitudinal tangencial para a determinação histométrica dos elementos axiais do xilema secundário. In: Anais do IV Congresso Florestal Estadual. Nova Prata, 1980. p. $180-184$.

MARCHIORI, J.N.C. Estudo anatômico de Feijoa sellowiana Berg Ciência e Natura, Santa Maria, v. 6, p. 117-125, 1984.a.

MARCHIORI, J.N.C. Anatomia da madeira de Eugenia involucrata DC. (Myrtaceae). Ciência e Natura, Santa Maria, v. 6, p. 127-136, 1984.b.

MARCHIORI, J.N.C. Anatomia descritiva da madeira do murtilho, Myrrhinium loranthoides (Hook. et Arn.) Burret (Myrtaceae). Rev Centro de Ciências Rurais, Santa Maria, v. 14 , n. 1 , p. $43-50,1984 . c$.

MARCHIORI, J.N.C. Anatomia descritiva da madeira de Myrceugenia myrtoides Berg. Ciência e Natura, Santa Maria, v. 9, p. 113-120, 1987.

MARCHIORI, J.N.C., MUÑIZ, G.I.B. de. Estudo anatômico da madeira de Myrciaria tenella (DC.) Berg. Ciência e Natura, Santa Maria, v. 9, p. 97-103, 1987

MARCHIORI, J.N.C., MUÑIZ, G.I.B. de. Estudo anatômico da madeira de Myrceugenia glaucescens (Camb.) Legr. et Kaus. Ciência e Natura, Santa Maria, v. 10, p. 105-113, 1988.

MATTOS, J.R. Myrtaceae do Rio Grande do Sul. Roessléria, v. 5, n. 2, p. 171-359, 1983.

METCALFE, C.R., CHALK, L. Anatomy of the Dicotyledons. Oxford: Clarendon Press, 1972. 1500 p.

RECORD, S.J., HESS, R.W. Timbers of The New World. New Haven: Yale University Press, 1949. 640 p.

SCHMID, R., BAAS, P. The occurrence of scalariform perforation plates and helical vessel wall thickenings in wood of Myrtaceae. IAWA Bull., 1984, v. 5, n. 3, p. 197-215. 